\title{
The Relationship between ALA16VAL Single Gene Polymorphism and Renal Cell Carcinoma
}

\author{
Dogan Atilgan, ${ }^{1}$ Bekir S. Parlaktas, ${ }^{1}$ Nihat Uluocak, ${ }^{1}$ Engin Kolukcu, ${ }^{1}$ \\ Fikret Erdemir, ${ }^{1}$ Huseyin Ozyurt, ${ }^{2}$ and Unal Erkorkmaz ${ }^{3}$ \\ ${ }^{1}$ Department of Urology, Gaziosmanpasa University Medical Faculty, Tokat 60100, Turkey \\ ${ }^{2}$ Department of Biochemistry, Gaziosmanpasa University Medical Faculty, Tokat 60100, Turkey \\ ${ }^{3}$ Department of Biostatistics and Medical Informatics, Medical Faculty, Sakarya University, Turkey \\ Correspondence should be addressed to Dogan Atilgan; datilgan@msn.com
}

Received 29 June 2013; Accepted 2 December 2013; Published 23 January 2014

Academic Editor: Axel S. Merseburger

Copyright (C) 2014 Dogan Atilgan et al. This is an open access article distributed under the Creative Commons Attribution License, which permits unrestricted use, distribution, and reproduction in any medium, provided the original work is properly cited.

\begin{abstract}
Objectives. The aim of this study was to investigate the association of RCC and Ala16Val polymorphism in Turkish patients with RCC. Materials and Methods. A total of 41 patients with RCC who underwent radical or partial nephrectomy in our clinic and 50 healthy volunteers living in the same geographic area were included in this study. DNA samples from serum of RCC patients and controls were genotyped for MnSOD polymorphism analysis. Genotype ratios and allele frequencies were compared between two groups and odd ratios with $95 \%$ confidence intervals were calculated statistically. A $P$ value of $<0.05$ was considered statistically significant. Results. There was a significant difference in the MnSOD genotype distributions between the RCC patients and the controls in terms of Ala/Ala+Ala/Val and Val/Val genotypes $(P=0.039)$. The Ala/Ala+Ala/Val genotypes were found significantly suspicious for RCC with an $\mathrm{OR}$ of $2.64(95 \% \mathrm{CI}=1.06-6.69, P=0.039)$. In addition, Ala allele was found significantly suspicious for RCC with an OR of 2.26 (95\% CI = 1.24-4.12, P = 0.009). Conclusion. Our study indicated that MnSOD Ala16Val polymorphism may be one of the many genetic factors for renal cancer susceptibility in Turkish patients.
\end{abstract}

\section{Introduction}

Renal cell carcinoma (RCC) is the most common malignancy of the kidney and it constitutes approximately $3 \%$ of all adult malignancies and more than $90 \%$ of renal cancers [1]. RCC originates from the tubular structures of the kidney and is classified into 4 main histological types. Of all types, the most common type seen clear cell renal cell carcinoma (ccRCC) accounts for about $75 \%$ of all RCC cases [2]. Cigarette smoking, body mass index, and heredity are the most important risk factors that are associated with RCC. Approximately, 4\% of all RCC are hereditary as well [3].

Single nucleotide polymorphism (SNP) is defined as a DNA sequence variation occurring when a single nucleotide, A, T, C, or G, in the genome differs between members of a biological species or paired chromosomes in a human [4]. The association of SNPs in genomes with various systemic diseases and malignancies has been shown in many previous studies. In addition to the SNPs in genes which provide production of superoxide dismutase (SOD), glutathione peroxidase (GPX), and paroxonase (PON), a wide range of human diseases like cancer, infectious diseases, autoimmune, neuropsychiatric, sickle-cell anemia, $\beta$ Thalassemia, and cystic fibrosis may result due to SNPs [5-7]. As a result, the diseases which develop due to different SNPs may become relevant pharmacogenomic targets for drug therapy [8]. The SNPs without an observable impact on the phenotype are still useful as genetic markers in genome-wide association studies, because of their quantity and the stable inheritance over generations [9].

The enzyme SOD is one of the most important members of the antioxidant defence system and it converts superoxide free radical $\left(\mathrm{O}_{2}\right)$ to hydrogen peroxide $\left(\mathrm{H}_{2} \mathrm{O}_{2}\right)$ [10]. MnSOD Ala16Val genotype (rs4880 SNP, present in exon 2 and substitutes a $\mathrm{C}>\mathrm{T}$ at position 2734 which changes the amino acid from alanine (Ala) to valine (Val) at position 16) has been 
investigated in numerous studies and associated with various systemic diseases and malignancies [11].

In this study, we aimed to investigate the association of RCC and Ala16Val polymorphism in Tokat region and according to our knowledge this is the first study in the literature which investigated Ala16 Val polymorphism in RCC.

\section{Materials and Methods}

After the approval of the local ethical committee permission, a total of 41 (29 males and 12 females) patients with RCC and who under went radical or partial nephrectomy operations in our urology clinic were included in this study. The control group included 50 healthy volunteers $(37$ men and 13 women), chosen at the same time, who were free of any chronic diseases, having no history of any cancer, and living in the same geographic area. They were matched with cases in age and gender. Smoking status and body mass index (BMI) of cases and controls were also evaluated. Tumor type, Fuhrman grade and tumor stage of the RCC patients were examined. Approximately $5 \mathrm{cc}$ of venous blood was taken from patients and controls for the determination of genotype.

2.1. Genotyping. Genomic DNA was extracted from the peripheral leukocytes of the collected EDTA-anticoagulated blood by the High Pure PCR Template Preparation Kit (Roche Molecular Biochemicals, Mannheim, Germany) according to the manufacturer's instructions. To identify MnSOD Ala-9Val SNPs, genotyping was performed using PCR amplification and polymorphisms were detected with hybridization probes labeled with fluorescent dyes (LightCycler 480 II Real-Time PCR System, Roche Diagnostics, Mannheim, Germany). Target fragments of the human MnSOD genes were amplified with specific primers. To detect the MnSOD Ala-9Val polymorphism, we applied $10 \mathrm{pmol}$ of the forward primer 50-CAGCCTGCGTAGACGGTCCC-30 and the reverse primer 50 CGTGGTGCTTGCTGTGGTGC-30, and $3 \mathrm{pmol}$ of the sensor probe 50 CTCCGGCTTTGGGGTATCTGfluorescein-30 and the anchor probe 50-LC Red 640 GCTCCAGGCAGAAGCACAGCCTCCp-30. The LC FastStart Master Hybridization Probes buffer (Roche Diagnostics Inc.) was used as a reaction buffer. All primers and hybridization probes were designed and synthesized by TIB MOLBIOL (Berlin, Germany). The genotypes were identified by running a melting curve with specific melting points (Tm). Wild type MnSOD Ala exhibits a Tm of $65 \pm 0.5^{\circ} \mathrm{C}$. The allele variant $\mathrm{MnSOD}$ Val exhibits a $\mathrm{Tm}$ of $56 \pm 0.5^{\circ} \mathrm{C}$. The PCR reaction was as follows: initial denaturation at $95^{\circ} \mathrm{C}$ for $10 \mathrm{~min}$, followed by 20 cycles at $95^{\circ} \mathrm{C}$ for $10 \mathrm{~s}$, and annealing at $60^{\circ} \mathrm{C}$. And then a melting curve was recorded by an initial increase in temperature to $95^{\circ} \mathrm{C}$, cooling the reaction mixture to $40^{\circ} \mathrm{C}$ at $20^{\circ} \mathrm{C} / \mathrm{s}$, holding for $30 \mathrm{~s}$, and then slowly heating it to $85^{\circ} \mathrm{C}$ at $0.1^{\circ} \mathrm{C} / \mathrm{s}$ with continuous acquisition. Finally, the fluorescence signal was plotted against temperature in real time to produce melting curves for each sample.
2.2. Statistical Analysis. Pearson's, Yates corrected, and Fisher's Chi-Square test were used to compare the genotypes and other categorical data between control and case groups. All categorical data were presented as count and percentage. Two independent samples $t$-test was used to compare the continuous data (age and BMI). Continuous data were presented as mean \pm standard deviation. A $P$ value $<0.05$ was considered significant. Analyses were performed using commercial software (IBM SPSS Statistics 20, SPSS Inc., an IBM Co., Somers, NY).

\section{Results}

The characteristics of the patients and control groups were presented in Table 1 . Mean age and female/male ratios were $62.18 \pm 8.44$ and $1 / 1.35$ in control group and $59.54 \pm$ 12.96 and 1/1.41 in patients group. Mean BMI was $26.02 \pm$ 3.95 and smoking rate was $26 \%$ in control group while in RCC group these values were $25.54 \pm 3.96$ and $26.859 \%$, respectively. There was no statistically significant difference between groups in terms of age, female/male ratio, BMI, and smoking status. Tumor types, Fuhrman grades, and clinical stage of the patients were presented in Table 2. Histologic subtyping revealed that there were $35(85.4 \%)$ clear cell RCC, 2 (4.9\%) papillary RCC, 2 (4.9\%) chromophobe RCC, and $2(4.9 \%)$ cystic RCC cases. Distribution of Mn-SOD (Ala16Val) polymorphisms in patients with renal cancer and controls was presented in Table 3. In the control group, the distributions of the MnSOD Ala16Val genotypes were consistent with the Hardy-Weinberg equilibrium (HWE). The distributions of the MnSOD genotypes in RCC patients were also consistent with the HWE. The Val/Val genotype was found in $46 \%$, the Ala/Val genotype was found in $38 \%$, and the Ala/Ala genotype was found in $16 \%$ of controls. In the RCC patients, the frequencies of the MnSOD genotypes were $24 \%$ for $\mathrm{Val} / \mathrm{Val}, 42 \%$ for Ala/Val, and $34 \%$ for Ala/Ala. In addition Ala dominant genotypes (Ala/Ala+Ala/Val) were found to be $76 \%$ in RCC group and 54\% in control group. There was a significant difference in the MnSOD genotype distributions between the RCC patients and the controls in terms of $\mathrm{Ala} / \mathrm{Ala}+\mathrm{Ala} / \mathrm{Val}$ and $\mathrm{Val} / \mathrm{Val}$ genotypes. The $\mathrm{Ala} / \mathrm{Ala}+\mathrm{Ala} / \mathrm{Val}$ genotypes were found significantly suspicious for RCC with an OR of 2.64 (95\% CI $=1.06-6.69, P=$ 0.039). In terms of allele frequencies, Ala allele frequency was found to be $55 \%$ and Val allele frequency was found to be $45 \%$ in RCC group. However Ala allele frequency was $35 \%$ and $\mathrm{Val}$ allele frequency was $65 \%$ in control group. Similarly, Ala allele was found significantly suspicious for RCC with an OR of 2.26 $(95 \% \mathrm{CI}=1.24-4.12, P=0.009)$.

\section{Discussion}

The etiology of renal cell carcinoma is still unclear. As in the other cancer types, oxidative stress may play a critical role in the development of RCC. The relationship between RCC and lipid peroxidation was shown in several reports $[12,13]$. Additionally, Lusini et al. showed that cytoplasmic SOD and 
TABLE 1: Demographic data of the groups.

\begin{tabular}{lcc}
\hline & \multicolumn{2}{c}{ Groups } \\
\hline Gender & Control $(n=50)$ & RCC $(n=41)$ \\
$\quad$ Male & $37(74.0)$ & $29(70.7)$ \\
Female & $13(26.0)$ & $12(29.3)$ \\
Age & $62,18 \pm 8,44$ & $59,54 \pm 12,96$ \\
BMI & $26,02 \pm 3,95$ & $25,54 \pm 3,96$ \\
Smoking & & \\
$\quad$ No & $37(74.0)$ & $30(73.2)$ \\
$\quad$ Yes & $13(26.0)$ & $11(26.8)$ \\
\hline
\end{tabular}

TABLE 2: Tumor characteristics of the RCC patients.

\begin{tabular}{lc}
\hline Pathology & \\
RCC & $40(97.6)$ \\
Cystic RCC & $1(2.4)$ \\
Tumor subtype & \\
Clear cell & $35(85.4)$ \\
Cystic & $2(4.9)$ \\
Chromophobe & $2(4.9)$ \\
Papillary & $2(4.9)$ \\
Mean tumor size & $6.00 \pm 3,36$ \\
Fuhrman scores & \\
1 & $11(26.8)$ \\
2 & $21(51.2)$ \\
3 & $6(14.6)$ \\
4 & $3(7.3)$ \\
Stage & \\
1 & $27(65.9)$ \\
2 & $9(22.0)$ \\
3 & $4(9.8)$ \\
4 & $1(2.4)$ \\
\hline
\end{tabular}

TABle 3: Distribution of Mn-SOD (Ala16Val) polymorphism in patients with RCC and controls.

\begin{tabular}{lcccc}
\hline Mn-SOD & $\begin{array}{c}\text { Patients } \\
n=41\end{array}$ & $\begin{array}{c}\text { Control } \\
n=50\end{array}$ & $P$ & $\begin{array}{c}\text { OR (95\% } \\
\text { CI) }\end{array}$ \\
\hline Mn-SOD & & & 0.05 & \\
ALA16VAL & & & & \\
$\quad$ Ala/Ala & $14[34 \%]$ & $8[16 \%]$ & & \\
$\quad$ Ala/Val & $17[42 \%]$ & $19[38 \%]$ & & \\
$\quad$ Val/Val & $10[24 \%]$ & $23[46 \%]$ & & \\
(Ala/Ala + Ala/val) & $31[76 \%]$ & $27[54 \%]$ & $\mathbf{0 . 0 3 9}$ & 2.64 \\
Val/Val & $10[24 \%]$ & $23[46 \%]$ & & $(1.06-6.69)$ \\
Allele frequency & & & $\mathbf{0 . 0 0 9 *}$ & 2.26 \\
$\quad$ Ala & $45[55 \%]$ & $35[35 \%]$ & & $(1.24-4.12)$ \\
Val & $37[45 \%]$ & $65[65 \%]$ & & \\
\hline
\end{tabular}

${ }^{*}$ There was statistically significant difference between groups.
GPX activities were lower in RCC tissues than in normal tissues [14].

The inability of elimination of the ROS has been associated with the development of many diseases and various types of cancer as well. Three different isoforms of SOD have been identified. SOD1 contains copper $(\mathrm{Cu})$ and zinc $(\mathrm{Zn})$ and is located in cytoplasm. SOD2 contains manganese and is located in mitochondria. SOD2 is the only antioxidant enzyme known existing in the mitochondria. Mitochondrion is the most important accumulating area of the ROS that is produced during normal cellular metabolism. Because of this reason SOD2 (MnSOD) becomes more important in antioxidant defence mechanism. SOD3 or extracellular SOD also consists of $\mathrm{Cu}$ and $\mathrm{Zn}$.

MnSOD is the most important enzyme that provide detoxification of the accumulated ROS in mitochondria and its gene is located at chromosome 6q25 [15]. Numerous studies have been identified that chromosome $6 \mathrm{q} 25$ has been deleted in many types of cancer. Therefore MnSOD has been accepted as a tumor suppressor gene by some authors [1620]. In addition, it has been shown that oxidative stress may be associated with carcinogenesis and genetic variants in the genes encoding the enzymes related to ROS detoxification have been found to affect individual susceptibility to cancer development [21-23]. In this study, we investigated Ala9Val gene polymorphism and evaluated its effect on RCC occurrence in Turkish population. Relationship between the levels of mitochondrial $\mathrm{H}_{2} \mathrm{O}_{2}-\mathrm{O}_{2}$ and carcinogenesis has been demonstrated in several studies [24-26]. According to Sutton et al. Ala form is targeted into mitochondria. The different structures of the variants may affect interactions with the Tim 23 import channel within the inner membrane that causes a reduced import in mitochondrial matrix and lower activity of SOD2 for the Val16 variant [27]. Hence, it is expected that the Val form would be associated with higher cancer risk. Nevertheless, association of Val form of SOD2 with higher cancer was reported only in a very few studies [28-31].

On the contrary, there were a lot of studies in the literature that advocated the presence of Ala allele as a risk factor for cancer. The reason of this opposition is still unclear. It was known that superoxide radicals dismutated to $\mathrm{H}_{2} \mathrm{O}_{2}-\mathrm{O}_{2}$ and SOD2 accelerated this reaction. Dasgupta et al. showed that increase in intracellular production of $\mathrm{H}_{2} \mathrm{O}_{2}$ by SOD2 was associated with decreased sensitivity to tumor necrosis factor- $\alpha$ mediated apoptosis. Therefore, as in the case of Val form, reduction of the SOD2 to enter mitochondrial matrix inhibits dismutation of superoxides to $\mathrm{H}_{2} \mathrm{O}_{2}$. Decreased level of $\mathrm{H}_{2} \mathrm{O}_{2}$ may lead to increased rate of programmed cell death ratio. As a result, the death of defective cells may supress the process of cancer development. This may be the possible cause of the association between Val form and lower risk of cancer [32].

The relationship between Ala/Ala genotype and cancer risk has been shown in many studies. Landi et al. found that the Ala/Ala genotype was associated with increased risk of malignant pleural mesothelioma [33]. In a study with high number of patients Millikan et al. reported that women with the Ala/Ala genotype had a significantly increased risk of 
breast cancer [34]. The variant Ala allele was also associated with increased risk of breast cancer among premenopausal women with lower antioxidant consumption $[35,36]$. The relationship between Ala9Val polymorphism and prostate cancer also has been investigated in many studies. Kang et al. reported that Ala/Ala and Ala/Val genotypes were associated with prostate cancer in Caucasians [37]. Similarly Ergen et al. determined that Ala/Ala genotype was significantly high in prostate cancer patients [38]. Additionally, ArsovaSarafinovska et al. identified that the Ala/Ala genotype was associated with a greater risk of prostate cancer being diagnosed under the age of 65 years [39].

The association of Ala/Ala genotype and aggressive behavior of tumor has also been studied previously. Mikhak et al. reported that Ala/Ala allele was significantly associated with more aggressive form of prostate cancer in men with low lycopene status [40]. Similarly, Woodson et al. also noted that Ala/Ala genotype was associated with high grade tumor in prostate cancer patients [41]. Ala allele was also associated with gastric cancer and gastric precancerous lesions [42]. Our study showed a significant association between RCC risk and the MnSOD Ala16Val gene polymorphism.

In conclusion, although it was studied with a very limited number of patients, this study indicated that Mn-SOD Ala16Val polymorphism may be one of the many genetic factors for renal cancer susceptibility in Turkish patients. It should be noted that Mn-SOD Ala16Val polymorphism in different populations showed variations due to ethnicity and various environmental factors should be considered in different geographic areas; therefore this result needs to be verified with further studies having larger sample size.

\section{Conflict of Interests}

The authors declare that there is no conflict of interests regarding the publication of this paper.

\section{Acknowledgments}

The authors are grateful for the assistance of Omer Ates M.D. (Department of Medical Biology, Gaziosmanpasa University Medical Faculty) in the genetic counseling. This study was supported by the Research Fund of Gaziosmanpasa University, Project no. 2012-09.

\section{References}

[1] S. H. Landis, T. Murray, S. Bolden, and P. A. Wingo, "Cancer Statistics, 1999," Ca: A Cancer Journal for Clinicians, vol. 49, no. 1, pp. 8-31, 1999.

[2] S. Störkel, J. N. Eble, K. Adlakha et al., "Classification of renal cell carcinoma: workgroup No. 1. Union Internationale Contre le Cancer (UICC) and the American Joint Committee on Cancer (AJCC)," Cancer, vol. 80, pp. 987-989, 1997.

[3] S. C. Clifford, A. H. Prowse, N. A. Affara, C. H. Buys, and E. R. Maher, "Inactivation of the von Hippel-Lindau (VHL) tumour suppressor gene and allelic losses at chromosome arm $3 p$ in primary renal cell carcinoma: evidence for a VHL-independent pathway in clear cell renal tumourigenesis," Genes Chromosomes Cancer, vol. 22, pp. 200-209, 1998.

[4] L. B. Barreiro, G. Laval, H. Quach, E. Patin, and L. QuintanaMurci, "Natural selection has driven population differentiation in modern humans," Nature Genetics, vol. 40, no. 3, pp. 340-345, 2008.

[5] V. M. Ingram, "A specific chemical difference between the globins of normal human and sickle-cell anæmia hæmoglobin," Nature, vol. 178, no. 4537, pp. 792-794, 1956.

[6] J. C. Chang and Y. W. Kan, " $\beta 0$ thalassemia, a nonsense mutation in man," Proceedings of the National Academy of Sciences of the United States of America, vol. 76, no. 6, pp. 28862889, 1979.

[7] A. Hamosh, T. M. King, B. J. Rosenstein et al., "Cystic fibrosis patients bearing both the common missense mutation Gly $\rightarrow$ Asp at codon 551 and the $\Delta$ F508 mutation are clinically indistinguishable from $\Delta$ F508 homozygotes, except for decreased risk of meconium ileus," American Journal of Human Genetics, vol. 51, no. 2, pp. 245-250, 1992.

[8] M. Fareed and M. Afzal, "Single nucleotide polymorphism in genome-wide association of human population: a tool for broad spectrum service," Egyptian Journal of Medical Human Genetics, vol. 14, no. 2, pp. 123-134, 2013.

[9] P. E. Thomas, R. Klinger, L. I. Furlong, M. HofmannApitius, and C. M. Friedrich, "Challenges in the association of human single nucleotide polymorphism mentions with unique database identifiers," BMC Bioinformatics, vol. 12, supplement 4, article S4, 2011.

[10] I. Fridovich, "The biology of oxygen radicals," Science, vol. 201, no. 4359 , pp. $875-880,1978$.

[11] J. S. Rosenblum, N. B. Gilula, and R. A. Lerner, "On signal sequence polymorphisms and diseases of distribution," Proceedings of the National Academy of Sciences of the United States of America, vol. 93, no. 9, pp. 4471-4473, 1996.

[12] M. Gago-Dominguez, J. E. Castelao, J.-M. Yuan, R. K. Ross, and M. C. Yu, "Lipid peroxidation: a novel and unifying concept of the etiology of renal cell carcinoma (United States)," Cancer Causes and Control, vol. 13, no. 3, pp. 287-293, 2002.

[13] M. Gago-Dominguez and J. E. Castelao, "Lipid peroxidation and renal cell carcinoma: further supportive evidence and new mechanistic insights," Free Radical Biology and Medicine, vol. 40, no. 4, pp. 721-733, 2006.

[14] L. Lusini, S. A. Tripodi, R. Rossi et al., "Altered glutathione antioxidant metabolism during tumor progression in human renalcell carcinoma," International Journal of Cancer, vol. 91, pp. 5559, 2001.

[15] A. Bag and N. Bag, "Target sequence polymorphism of human manganese superoxide dismutase gene and its association with cancer risk: a review," Cancer Epidemiology Biomarkers and Prevention, vol. 17, no. 12, pp. 3298-3305, 2008.

[16] L. W. Oberley and G. R. Buettner, "Role of superoxide dismutase in cancer: a review," Cancer Research, vol. 39, no. 4, pp. 1141-1149, 1979.

[17] T.-C. Chuang, J.-Y. Liu, C.-T. Lin et al., "Human manganese superoxide dismutase suppresses HER2/neu-mediated breast cancer malignancy," FEBS Letters, vol. 581, no. 23, pp. 44434449, 2007.

[18] J. J. Cullen, C. Weydert, M. M. Hinkhouse et al., "The role of manganese superoxide dismutase in the growth of pancreatic adenocarcinoma," Cancer Research, vol. 63, no. 6, pp. 1297-1303, 2003. 
[19] H. Hu, M.-L. Luo, X.-L. Du et al., "Up-regulated manganese superoxide dismutase expression increases apoptosis resistance in human esophageal squamous cell carcinomas," Chinese Medical Journal, vol. 120, no. 23, pp. 2092-2098, 2007.

[20] Y. Soini, M. Vakkala, K. Kahlos, P. Pääkkö, and V. Kinnula, "MnSOD expression is less frequent in tumour cells of invasive breast carcinomas than in in situ carcinomas or non-neoplastic breast epithelial cells," Journal of Pathology, vol. 195, no. 2, pp. 156-162, 2001.

[21] M. Valko, M. Izakovic, M. Mazur, C. J. Rhodes, and J. Telser, "Role of oxygen radicals in DNA damage and cancer incidence," Molecular and Cellular Biochemistry, vol. 266, no. 1-2, pp. 37-56, 2004.

[22] J. E. Klaunig and L. M. Kamendulis, "The role of oxidative stress in carcinogenesis," Annual Review of Pharmacology and Toxicology, vol. 44, pp. 239-267, 2004.

[23] J. E. Klaunig, Y. Xu, S. Bachowski, and J. Jiang, "Free-radical oxygen-induced changes in chemical carcinogenesis," in Free Radical Toxicology, K. B. Wallace, Ed., pp. 375-400, Taylor \& Francis, London, UK, 1997.

[24] A. Gorman, A. McGowan, and T. G. Cotter, "Role of peroxide and superoxide anion during tumour cell apoptosis," FEBS Letters, vol. 404, no. 1, pp. 27-33, 1997.

[25] C. F. Nathan and Z. A. Cohn, "Antitumor effects of hydrogen peroxide in vivo," Journal of Experimental Medicine, vol. 154, no. 5, pp. 1539-1553, 1981.

[26] M. López-Lázaro, "Dual role of hydrogen peroxide in cancer: possible relevance to cancer chemoprevention and therapy," Cancer Letters, vol. 252, no. 1, pp. 1-8, 2007.

[27] A. Sutton, H. Khoury, C. Prip-Buus, C. Cepanec, D. Pessayre, and F. Degoul, "The Ala16Val genetic dimorphism modulates the import of human manganese superoxide dismutase into rat liver mitochondria," Pharmacogenetics, vol. 13, no. 3, pp. 145157, 2003.

[28] R. J. Hung, P. Boffetta, P. Brennan et al., "Genetic polymorphisms of MPO, COMT, MnSOD, NQO1, interactions with environmental exposures and bladder cancer risk," Carcinogenesis, vol. 25, no. 6, pp. 973-978, 2004.

[29] M. Bergman, M. Ahnström, P. P. Wegman, and S. Wingren, "Polymorphism in the manganese superoxide dismutase (MnSOD) gene and risk of breast cancer in young women," Journal of Cancer Research and Clinical Oncology, vol. 131, no. 7, pp. 439-444, 2005.

[30] J. Zejnilovic, N. Akev, H. Yilmaz, and T. Isbir, "Association between manganese superoxide dismutase polymorphism and risk of lung cancer," Cancer Genetics and Cytogenetics, vol. 189, no. 1, pp. 1-4, 2009.

[31] G. Liu, W. Zhou, S. Park et al., "The SOD2 Val/Val genotype enhances the risk of nonsmall cell lung carcinoma by p53 and XRCC1 polymorphisms," Cancer, vol. 101, no. 12, pp. 2802-2808, 2004.

[32] J. Dasgupta, S. Subbaram, K. M. Connor et al., "Manganese superoxide dismutase protects from TNF- $\alpha$-induced apoptosis by increasing the steady-state production of H2O2," Antioxidants and Redox Signaling, vol. 8, no. 7-8, pp. 1295-1305, 2006.

[33] S. Landi, F. Gemignani, M. Neri et al., "Polymorphisms of glutathione-S-transferase M1 and manganese superoxide dismutase are associated with the risk of malignant pleural mesothelioma," International Journal of Cancer, vol. 120, no. 12, pp. 2739-2743, 2007.

[34] R. C. Millikan, J. Player, A. R. de Cotret et al., "Manganese superoxide dismutase Ala-9Val polymorphism and risk of breast cancer in a population-based case-control study of African Americans and whites," Breast Cancer Research, vol. 6, no. 4, pp. R264-R274, 2004.

[35] K. M. Egan, P. A. Thompson, L. Titus-Ernstoff, J. H. Moore, and C. B. Ambrosone, "MnSOD polymorphism and breast cancer in a population-based case-control study," Cancer Letters, vol. 199, no. 1, pp. 27-33, 2003.

[36] C. B. Ambrosone, J. L. Freudenheim, P. A. Thompson et al., "Manganese superoxide dismutase (MnSOD) genetic polymorphisms, dietary antioxidants, and risk of breast cancer," Cancer Research, vol. 59, no. 3, pp. 602-606, 1999.

[37] D. Kang, K.-M. Lee, K. P. Sue et al., "Functional variant of manganese superoxide dismutase (SOD2 V16A) polymorphism is associated with prostate cancer risk in the prostate, lung, colorectal, and ovarian cancer study," Cancer Epidemiology Biomarkers and Prevention, vol. 16, no. 8, pp. 1581-1586, 2007.

[38] H. Ergen, F. Narter, Ö. Timirci, and T. Isbir, "Effects of manganase superoxide dismutase Ala-9Val polymorphism on prostate cancer: a case-control study," Anticancer Research, vol. 27, no. 2, pp. 1227-1230, 2007.

[39] Z. Arsova-Sarafinovska, N. Matevska, D. Petrovski et al., "Manganese superoxide dismutase (MnSOD) genetic polymorphism is associated with risk of early-onset prostate cancer," Cell Biochemistry and Function, vol. 26, no. 7, pp. 771-777, 2008.

[40] B. Mikhak, D. J. Hunter, D. Spiegelman et al., "Manganese superoxide dismutase (MnSOD) gene polymorphism, interactions with carotenoid levels and prostate cancer risk," Carcinogenesis, vol. 29, no. 12, pp. 2335-2340, 2008.

[41] K. Woodson, J. A. Tangrea, T. A. Lehman et al., "Manganese superoxide dismutase (MnSOD) polymorphism, $\alpha$ tocopherol supplementation and prostate cancer risk in the Alpha-Tocopherol, Beta-Carotene Cancer Prevention Study (Finland)," Cancer Causes and Control, vol. 14, no. 6, pp. 513518, 2003.

[42] J.-F. Yi, Y.-M. Li, T. Liu et al., "Mn-SOD and cuZn-SOD polymorphisms and interactions with risk factors in gastric cancer," World Journal of Gastroenterology, vol. 16, no. 37, pp. 4738-4746, 2010. 


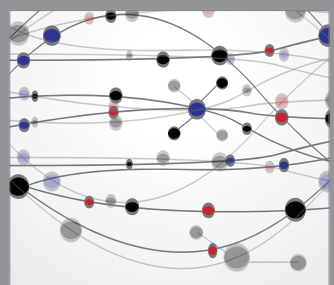

The Scientific World Journal
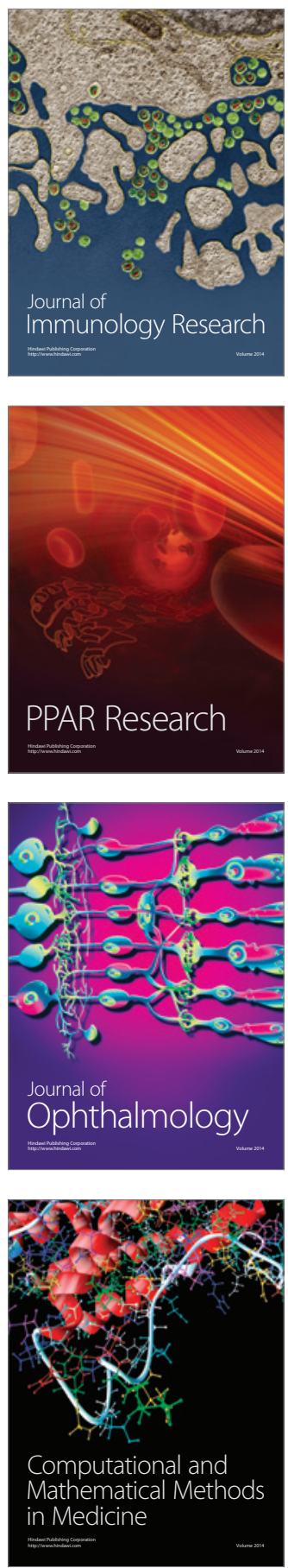

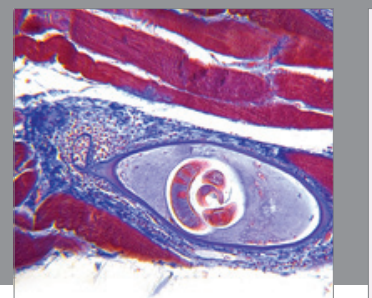

Gastroenterology

Research and Practice
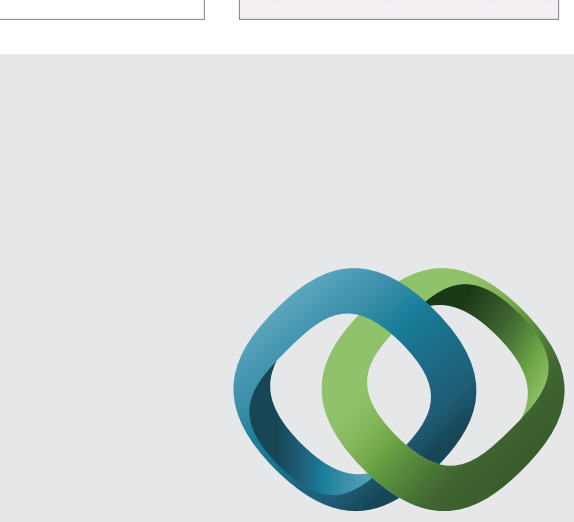

\section{Hindawi}

Submit your manuscripts at

http://www.hindawi.com
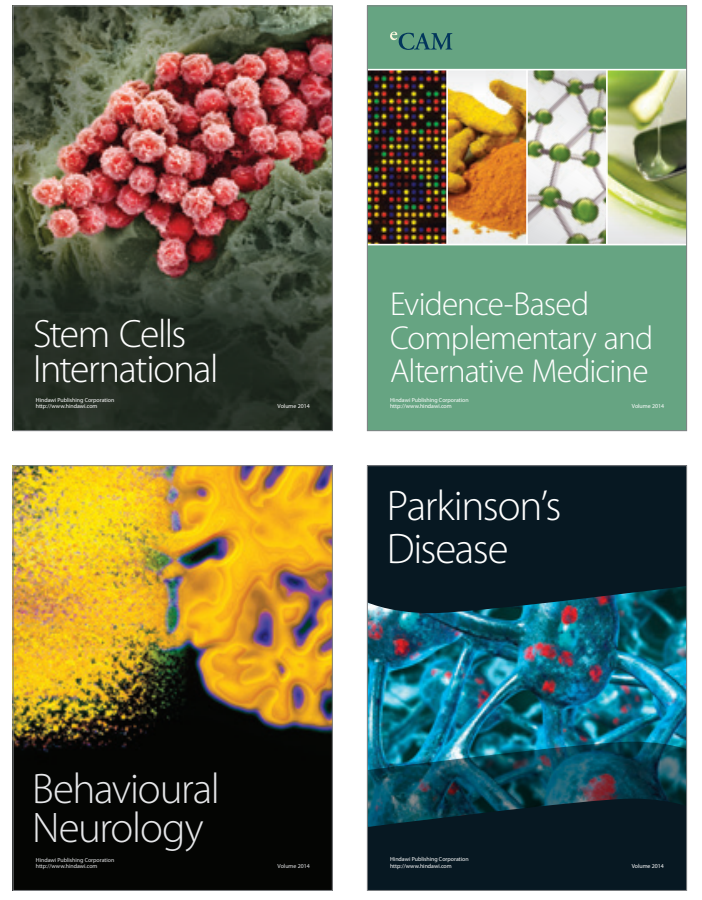
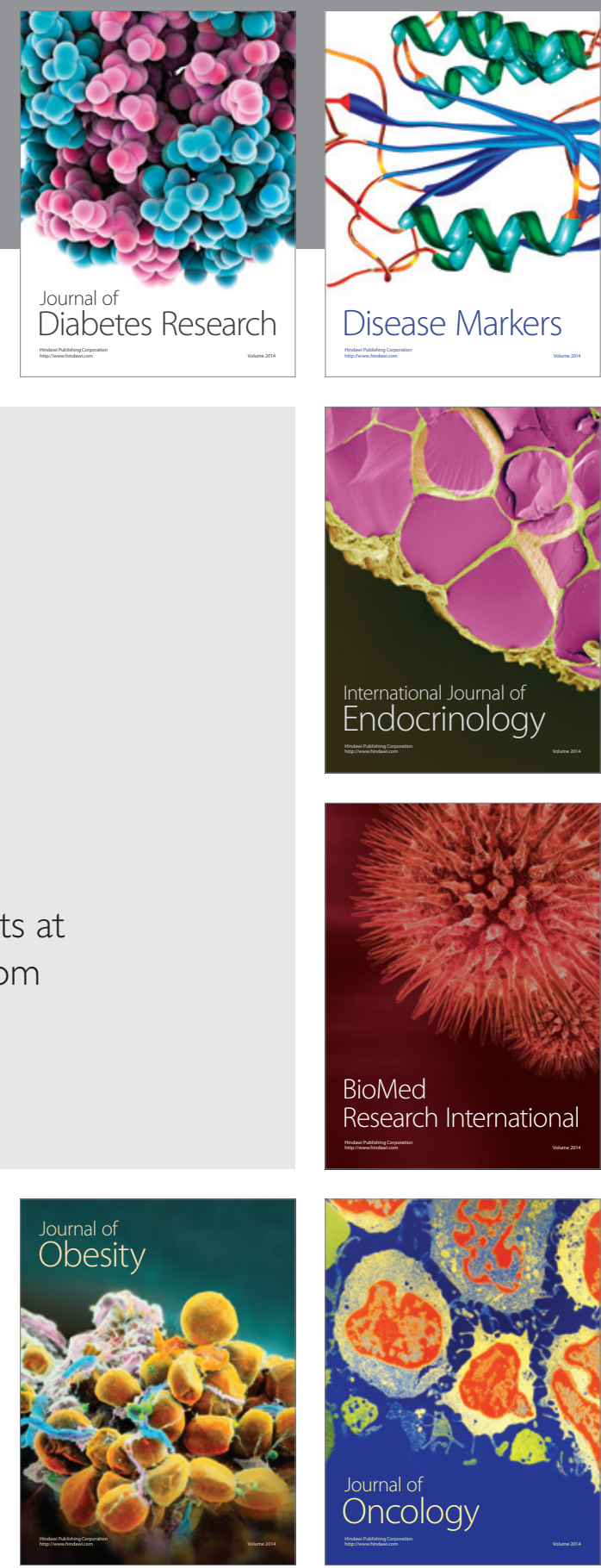

Disease Markers
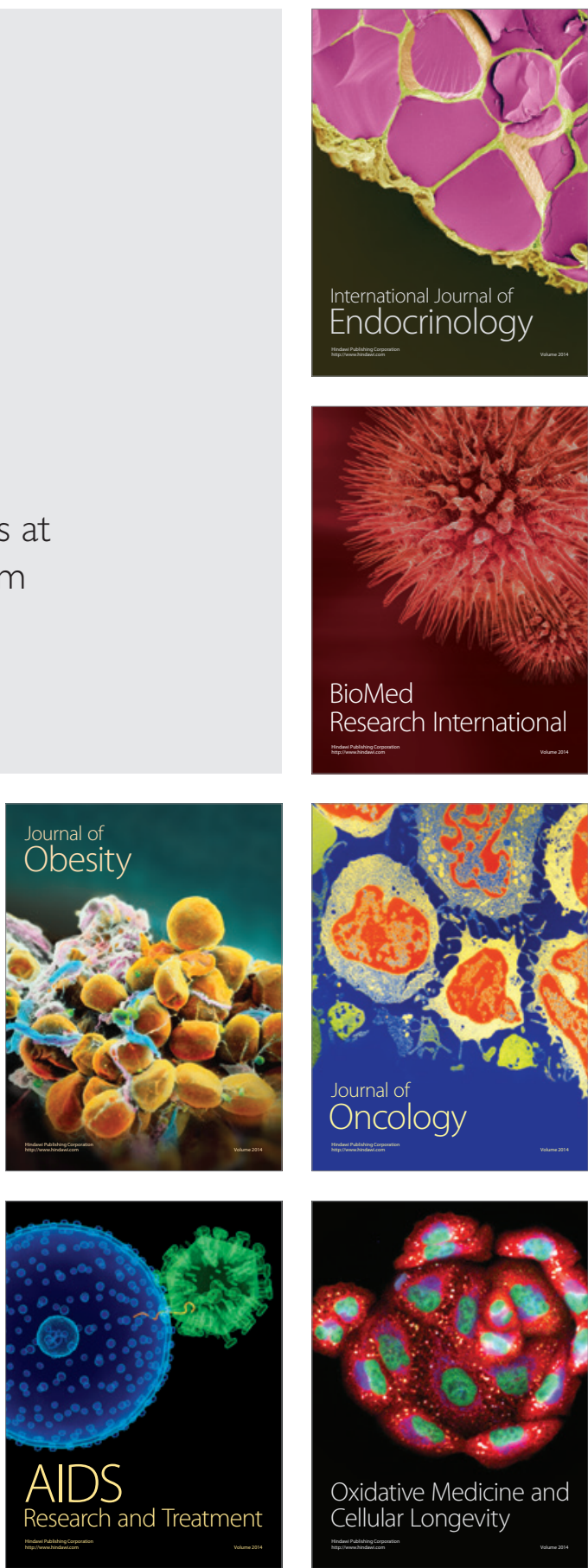